\title{
Is the use of automated artificial manual breathing unit resuscitators justified during a pandemic mechanical ventilator crisis?
}

\author{
Kamna Kakkar ${ }^{1}$, Bhavna Gupta ${ }^{2}$ \\ 'Department of Anaesthesiology, Pandit Bhagwat Dayal Sharma Post Graduate Institute of Medical Sciences, Rohtak, Haryana; ${ }^{2}$ Department of \\ Anaesthesiology, All India Institute of Medical Sciences, Rishikesh, India
}

\section{Dear Editor:}

Coronavirus disease-19 (COVID-19) has an acute onset, mainly affects the respiratory tract, and can progress to acute respiratory distress syndrome, which necessitates management in the intensive care unit. This pandemic has created an unprecedented need for ventilators across the globe. Of every 100 patients diagnosed, at least three patients require mechanical ventilation [1]. This has led to a widespread demand for ventilators in a bid reduce mortality rates. In the United States alone, there is an acute ventilator shortage of 300,000-700,000 units according to the Centers for Disease Control and Prevention Pandemic Response Plans Report [2]. This has prompted policy makers to settle for cheaper alternatives for mechanical ventilators, specifically automated artificial manual breathing units (AMBU) bags or resuscitators. An automated AMBU resuscitator is a device with a built-in mechanism that alternately squeezes and releases the AMBU bag at a specific frequency in a cyclical fashion, thus obviating the need for a person to do the same (Figure 1). Many manufacturers have begun producing automated AMBU bags, which are light weight, self-contained, rechargeable or battery powered, and provide controlled breaths to the patient. They claim to provide cost-effective ventilation in times of a pandemic crisis like COVID-19. When compared to its manual counterpart, automated AMBU bags do provide an advantage to healthcare workers in that they are hands-free, allowing staff to perform other critical tasks relevant to patient care while avoiding high intra-thoracic pressure and gastric insufflation, which may be associated with manually bagging patients.

However, the question arises: should automated AMBU resuscitators be accepted as an alternative to traditional mechanical ventilators? Are they the only hope during the current times of extreme ventilator shortage? This pandemic has led to the realization that when a hospital has used up all ventilators, it becomes imperative to patient survival to manually bag the patient or look for alternatives. Thus, automated AMBU bags may serve as a bridge device during ventilator shortages and help physicians triage patients, as most modern automated versions are able to detect excessive pressure and prevent overinflation of the lungs. Because automated AMBU bags are cheap, simple, light weight, portable, battery powered or plug in, have single or few knobs to control variables, and are easily assembled, they may be particularly useful during this pandemic crisis.

When settling for low cost, we must acknowledge the extent to which it sacrifices the safety

\section{Letter to the Editor}

Received: May 28, 2020

Revised: July 6, 2020

Accepted: July 9, 2020

Corresponding author Bhavna Gupta

Department of Anaesthesiology,

All India Institute of medical

Sciences, Rishikesh 249203,

Uttaranchal, India

Tel: +91-8527686660

Fax: $+91-1126853108$

E-mail:bhavna.kakkar@gmail.com

Copyright (@) 2020 The Korean Society of Critical Care Medicine

This is an Open Access article distributed under the terms of Creative Attributions Non-Commercial License (https:// creativecommons.org/li-censes/by-nc/4.0/) which permits unrestricted noncommercial use, distribution, and reproduction in any medium, provided the original work is properly cited. 


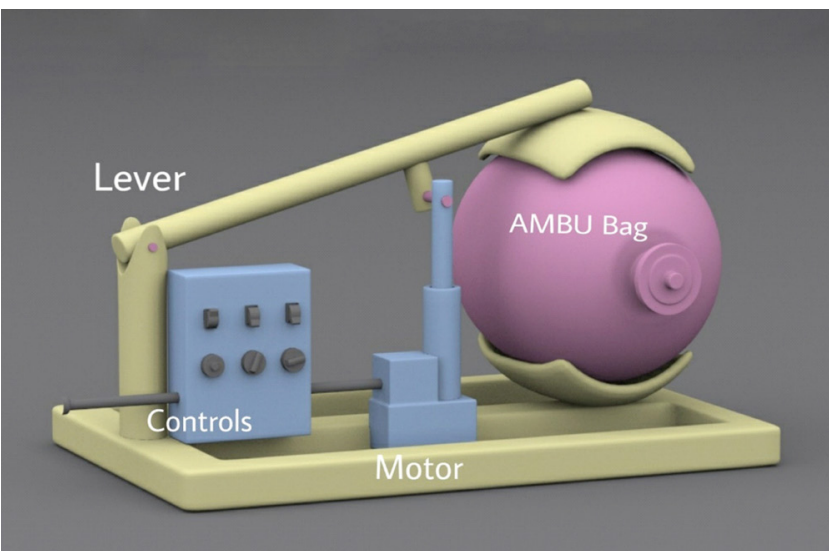

Figure 1. Three-dimensional rendition of an automated artificial manual breathing units (AMBU) bag resuscitator.

of patients. When we are heading towards technological advancements in the form of adaptive neural mechanisms, automatic tube compensation, and proportional assist ventilation modes, should we still rely on basic mechanical ventilation in the form of fixed tidal volume and respiratory rate? This poses a major question on safety of widespread use of automated AMBU resuscitators. The material used is another challenge as we have not determined the durability of these low cost ventilators, the repercussions of wear and tear, the effectiveness of the cleaning methods employed to disinfect these devices and their effects on viral spread, as well as other parameters. These devices could prove to be a fire hazard as oxygen can corrode materials. The pandemic may not last long but procuring a huge amount of these makeshift devices may not be a great option for long term. Also, in COVID-19 cases, these automated ventilators may not be able to provide lung protective ventilation; some newer versions of these devices can closely control tidal volume, respiratory rate inspiratory pressure, inspiratory:expiratory ratio, and positive endexpiratory pressure, but additional monitoring of peak inspiratory pressure, plateau pressure, compliance, filtration, and adaptation is grossly lacking. They do not detect spontaneous breathing triggers and may lead to disuse weakening of respiratory muscles as a consequence. They are not standardized and employ crude mechanics. Ventilation is not just simply blowing air into a patient's lungs. This automated self-inflating resuscitation bag must also be subject to appropriate scrutiny to evaluate its performance before approval for widespread clinical use. A number of variables should be used to judge the performance of a ventilator device. [3] There is enough evidence to prove that unmonitored ventilation causes more harm than good.
Limitation of resources is a critical issue in this COVID-19 pandemic, which can lead to worse morbidity and mortality. It is important to respect the limitations of this device, and not favor the lower costs and ready availability of these devices over their potentially fatal risks and the lack scientific evidence "for" and "against" the same. Modern critical care is complex and artificial ventilation is only one component. In a pandemic crisis, all resources are scarce including human resources, hospital beds, and monitoring devices; therefore, the use of artificial mechanical ventilation support devices should have highest level of scientific evidence, in order to prevent any catastrophic clinical situations that may worsen an already precarious situation. Automated AMBU resuscitators should be strongly discouraged and not considered a valid substitute to mechanical ventilators. If they are used at all, it must be for a limited period of time, or as a last resort until a standard mechanical ventilator becomes available. Such use should only take place after safety checks and standardization, in line with the scientific evidence available, to prevent any iatrogenic complications.

\section{CONFLICT OF INTEREST}

No potential conflict of interest relevant to this article was reported.

\section{ACKNOWLEDGMENTS}

We would like to thank Sh. Aman Taneja, Visual Beats, India (www.visualbeats.in) for creating 3D rendition of Automated AMBU bag resuscitator for this article.

\section{ORCID}

Kamna Kakkar https://orcid.org/0000-0002-8448-9450

Bhavna Gupta https://orcid.org/0000-0002-3108-0408

\section{AUTHOR CONTRIBUTIONS}

Conceptualization: all authors. Data curation, Formal analysis, Methodology, Writing-original draft, review \& editing: BG.

\section{REFERENCES}

1. Meng L, Qiu H, Wan L, Ai Y, Xue Z, Guo Q, et al. Intubation and ventilation amid the COVID-19 outbreak: Wuhan's experience. Anesthesiology 2020;132:1317-32. 
2. Patrone D, Resnik D. Pandemic ventilator rationing and appeals processes. Health Care Anal 2011;19:165-79.

3. Khoury A, De Luca A, Sall FS, Pazart L, Capellier G. Perfor- mance of manual ventilation: how to define its efficiency in bench studies? A review of the literature. Anaesthesia 2015;70: 985-92. 